\title{
PREVENTIVE AND EDUCATIONAL PERFORMANCE OF THE BREAST LEAGUE IN THE MEETING OF ACADEMIC LEAGUES (ELA)
}

Pedro Henrique de Ávila Perillo', Júlio Montes Garcia Barbosa', Matheus Leão Tavares Costa', Paula Oliveira Caetano Queiroz ${ }^{1}$, Lucas Nunes da Silva', Rosemar Macedo Sousa Rahal ${ }^{1,2}$

${ }^{1}$ Faculdade de Medicina, Universidade Federal de Goiás - Goiânia (GO), Brazil.

${ }^{2}$ CORA - Centro Avançado de Diagnóstico da Mama, Hospital das Clínicas, Universidade Federal de Goiás - Goiânia (GO), Brazil.

Objectives: To report the experience of the Liga da Mama (Breast League) of the UFG in the Academic Leagues Meeting (ELA) and the findings found during the service to the population. Methods: During the event, the Breast League developed a single questionnaire to compose a final database. We inquired about the personal and family history of breast cancer, as well as risk factors such as hormone therapy, and prevention, such as total breastfeeding time. All women over 40 or who had a personal or family history of breast cancer were referred for physical examination, performed by a medical professional in a suitable room. Results: 65 women between the ages of 13 and 86 years were attended at the Information Stand of the Breast League. Of these, 57 had some risk factor (age over 40 years, family history of breast cancer, hormone replacement therapy for more than 5 years, or palpable nodules) and were referred for physical examination of the breasts. 4 women refused physical examination, therefore 53 were examined. At the examination, 6 women had some findings: 2 benign findings of the right accessory breast and 4 suspect findings ( 1 adolescent 13 years old with bilateral periareolar scaly lesions, 2 females over 40 years with fixed nodules in the lower left quadrant, and 1 female with crystalline papillary discharge on the right). All women with suspected findings were referred to the local health service. Conclusion: The action developed by the Breast League met its primary objectives: promoting the health and well-being of the population, through preventive and educational, humanized, and multidisciplinary activities, providing knowledge and experience to every academic body that compose it. In addition, the League was able to use practical methodologies to give, to the collected data, applicability in scientific productions. 